\title{
Combustion Characteristics of A Wood Pellet Made of Albizia Chinensis and Rice Husk
}

\author{
Lilis Yuliati \\ Mechanical Engineering Department \\ Brawijaya University \\ MT Haryono 167, Malang, Indonesia \\ lilis_y@ub.ac.id \\ Nurkholis Hamidi \\ Mechanical Engineering Department \\ Brawijaya University \\ MT Haryono 167, Malang, Indonesia
}

Rafif Ezrha Pragiwaka Mechanical Engineering Department Brawijaya University MT Haryono 167, Malang, Indonesia

\begin{abstract}
To reduce dependence on fossil fuel, biomass, e.g. the wood pellet, has been developed in recent years. Indonesia has an abundant source of biomass, e.g. wood and rice husk. This work investigates the combustion characteristics of the wood pellet made of Albizia Chinensis and rice husk. The analyzed combustion properties are ignition delay time, the mass of residue, combustion duration, combustion rate, maximum flame temperature, During the experiment, the rice husk content varies between 0 to 50\%. As the rice husk content increases from 0 to $50 \%$, the ignition delay time increases from 6 to 9.9 seconds, the mass of residue increases from 21.2 to $45 \%$ and the combustion rate decreases from 0.55 to 0.52 $\mathrm{g} / \mathrm{min}$. In addition, higher rice husk content also decreases the maximum temperature.
\end{abstract}

Keywords: Wood Pellet, Combustion Charasteristics, Albizia Moluccana, Risk Husk.

\section{INTRODUCTION}

The use of renewable energy should be further increased to decrease dependence on fossil fuels and greenhouse gas emissions. Of much alternative renewable energy, biomass has significant potential to be developed and used in Indonesia. Biomass which is derived from plants can be transformed into bioethanol, biodiesel or briquette, and wood pellet $[1,2]$. Wood pellet can be more developed in the future as a substitute for coal in many combustion processes. The processing and use of wood pellet in Indonesia have been significantly growing in recent years as the government of the Republic of Indonesia is eager to achieve 23\% renewable energy use in 2025 to decrease $\mathrm{CO}_{2}$ emissions [3]. In addition to its net-zero $\mathrm{CO}_{2}$ emissions and its low price, since the raw materials are from wastes of sawmill and furniture factory, combustion of wood pellet also benefits to the environment since it releases relatively low harmful elements, e.g. $\mathrm{SO}_{2}$. Challenges, however, remain for wood pellet application in the combustion process, e.g. due to its high water content, high fly ash content, low calorific value, high moisture absorption and much smoke generated during combustion. To address these challenges, Kluska et al. [4] suggested wood processing before wood pellet production. In addition, an advanced combustion system, e.g. using a screw feeder, can also be applied.

In Indonesia, promising applications of wood pellet are as fuel for low to medium capacity boilers in industry, as coal mixture in co-firing power plants and as stove fuel at household and small to medium enterprises. Thus, the demand for wood pellet has been increasing in recent years but sawdust supply, as raw material for wood pellet production, from the sawmill and furniture industry, is limited. For this reason, searching for other raw materials for wood pellet production is important. The agriculture sector, particularly paddy fields, produces a significant amount of wastes as rice straw and husk. They can be a potential source for wood pellet production. Remain challenges, however, since rice husk has low calorific value, high ash content, and low lignin content [5]. Thus, wood pellet added with rice husk has lower flame temperature, produces high ash amount and is easy to break up due to low content of binding agent. Many researchers have been worked out to increase the quality and combustion characteristics of wood pellets. Liu et al. [6] concluded that the addition of bamboo particles more than $60 \%$ to rice straw decreases ash content up to $8 \%$ and increases the calorific value up to $17.5 \mathrm{~kJ} / \mathrm{g}$. Rios-Badran et al. [7] reported that the addition of wheat straw, up to $50 \% \mathrm{wt}$, to rice husk can increase calorific value and decrease ash content.

This study is to investigate the influence of rice husk on combustion characteristics of wood pellet made 
of Albizia Chinensis. The investigated combustion characteristics include ignition delay time, a residual mass of combustion, ignition duration, combustion rate, flame visualization and combustion temperature. In the end, it is expected to acquire information about the optimum amount of rice husk added so that good combustion characteristics, particularly combustion rate and temperature, can be achieved.

\section{MATERIAL AND METHOD}

The wood pellet was made of Albizia Chinensis wood and rice husk. Rice husk mass added was varied between 10 to $50 \%$ wt with $10 \%$ wt increment. Pellet is in cylinder form with a size of $8 \mathrm{~mm}$ diameter and $20 \mathrm{~mm}$ height. A single wood pellet was placed in the combustion chamber and the ignition process use flame fuelled by LPG (Figure 1). Distance between the burner and the bottom part of pellet is $15 \mathrm{~mm}$. Air for combustion reaction flows from the compressor and its flow is measured with the flow meter. During ignition, the flow of LPG and air are constant at $11.5 \mathrm{~mL} / \mathrm{min}$ and $500 \mathrm{~mL} / \mathrm{min}$., respectively. A cylindrical burner with inner and outer diameter of 3.5 and $5 \mathrm{~mm}$ are installed on the end of Y/connector. After the wood pellet was combusted, LPG and airflow are stopped. The ignition delay time is determined since the burner was lighted out until the flame of the wood pellet achieved $10 \mathrm{~mm}$ height. The combustion duration was determined since the flame for the LPG burner was stopped until the flame outage of the wood pellet.

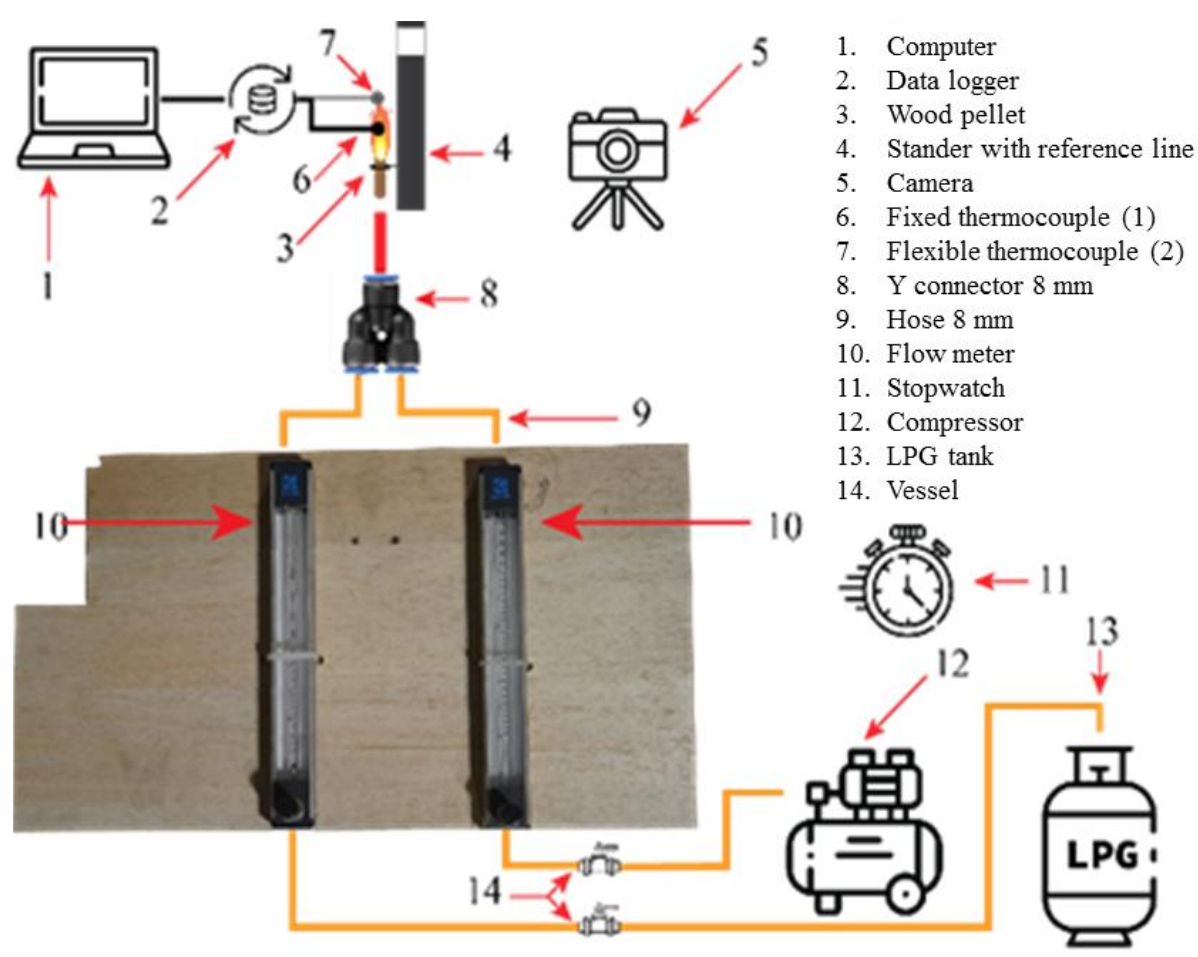

Figure 1: Experimental set up in this study

The distance between the video camera and the pellet is $700 \mathrm{~mm}$. Time recording was worked out using a stopwatch from the ignition of the burner until the flame of wood pellet and a linear scale measured the length of the flame. For visual analysis, this process was also recorded by a video with a frequency of 25 frames per second (fps) and its result is converted into pictures by using Adobe Premiere Pro 2017. Dimensional analysis of flame was using ImageJ software. Two type $\mathrm{K}$ thermocouples measured the temperature of the combustion chamber every 1 second and the result was analyzed by the data logger and computer. A flexible thermocouple is used here due to location change for temperature measurement. Mass analysis was worked out twice, i.e. before combustion and after the flame was completely outage. Combustion rate $(\mathrm{R})$ was determined by dividing the mass difference after the flame outage $\left(\mathrm{m}_{\text {end }}\right)$ and before the combustion $\left(\mathrm{m}_{\text {initial }}\right)$ with the combustion duration $(\Delta \mathrm{t})($ eq. 1$)$.

$$
\mathrm{R}=\frac{\mathrm{m}_{\mathrm{end}}-\mathrm{m}_{\text {initial }}}{\Delta \mathrm{t}}
$$




\section{RESULT AND DISCUSSION}

\subsection{Ignition delay time}

The ignition delay time is defined as the duration of wood pellet combustion which is determined from the heating or the burner ignition until the appearance of flame on the wood pellet. The heating process uses a cylindrical burner with a $5 \mathrm{~mm}$ diameter. There are several steps before the flame on the wood pellet commences. In the beginning, heat vaporizes moisture in the wood pellet and this process occurs at $100{ }^{\circ} \mathrm{C}$. After that, the temperature of the wood pellet increases and volatile matter vaporizes. Elements in volatile matter form a combustible mixture and this combustible mixture creates flame if it achieves its self-ignition temperature.

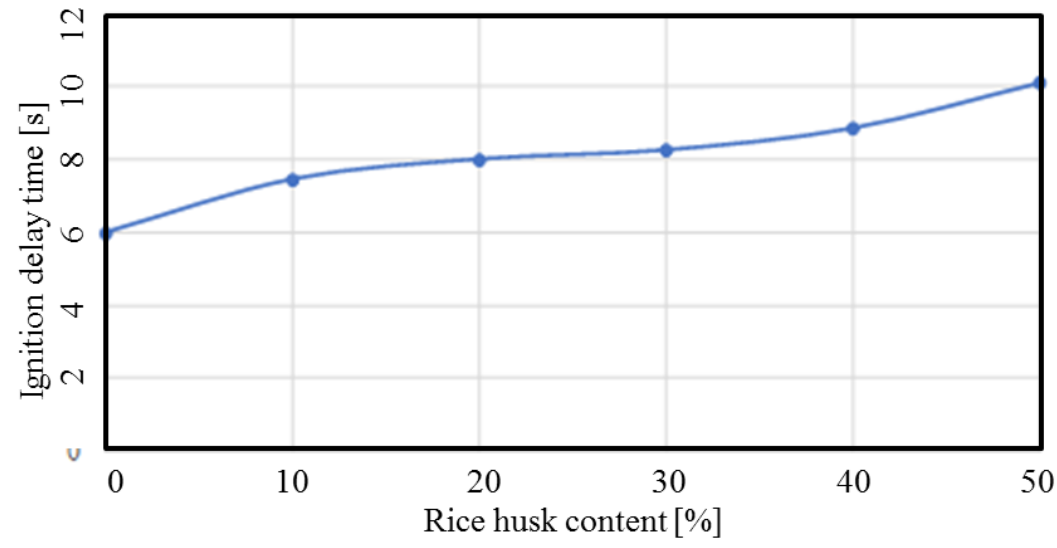

Figure 2: Influence of rice husk content on the ignition delay time

As a reference value, the ignition delay time is 6 seconds when no rice husk is added (Figure 2). As rice husk content increases, the ignition delay time increases. The highest ignition delay time of 10.1 seconds occurs for $50 \%$ rice husk content. Volatile matters are comprised of elements which easily evaporate, e.g. hydrogen, methane, nitrogen, which contribute to easier flame creation. Volatile matters of rice husk are lower than Albizia Chinensis. Therefore, higher content of rice husk results in lower total volatile matters of the mixture. When sufficient heat is available, volatile matters vaporize and create a mixture between fuel and air. After the fuel and air mixture reaches a particular amount, activation energy triggers flame creation. Thus, the ignition strongly depends on the above prerequisite conditions. In this study, the igniter was not directly turned off after flame creation. This is to prevent flame outage since heat due to pellet combustion is still not sufficient as the activation energy for stable combustion. After the flame height was more than $10 \mathrm{~mm}$, the igniter could be turned off since the flame was considered stable.

\subsection{Mass of combustion residue}

In this study, two data for the mass of combustion residue were gathered (Figure 3). The first one was gathered directly after the flame outage. Meanwhile, the second data was after the wood pellet achieved room temperature. In general, combustion residue consists of ash and incombustible matter. Ash is categorized as part of the wood pellet which cannot be combusted while the incombustible matter is part of the wood pellet which has not yet been combusted. In perfect combustion, no incombustible matter exists. The mass of combustion residue, therefore, consists of only ash mass.

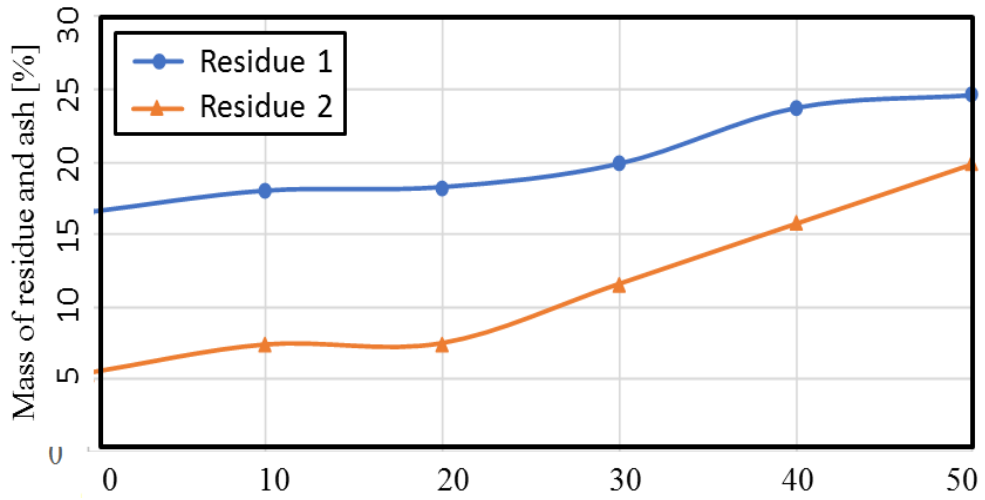

Figure 3: Influence of rice husk content on mass of residue 
As shown, the higher content of rice husk results in a higher mass of combustion residue, both mass of residue 1 and mass of residue 2 . When no rice husk was added, the mass of residue 1 and the mass of residue 2 are $16.5 \%$ and $5.4 \%$, respectively. The highest residue mass occurs for rice $50 \%$ husk content where mass of residue 1 and mass of residue 2 are $24 \%$ and 19.9, respectively. This is due to the higher ash content in rice husk compared to Albizia Chinensis. When incombustible ash remains in the wood pellet, it decreases combustion temperature since it absorbs combustion heat. Although the mass of residue 1 still contains combustible elements, the flame already outages due to no presence of combustible mixture around the wood pellet. This circumstance then leaves incombustible fixed carbon in the wood pellet. In good combustion, all fixed carbon is perfectly combusted and mass of residue 2 equals ash mass. In bad combustion, however, mass of residue 2 still contains combustible elements which result in a higher mass of residue 2 than ash mass. Nevertheless, increasing residue mass with increasing rice husk content is also due to increasing incombustible elements in the wood pellet.

The difference between the mass of residue 1 and the mass of residue 2 decreases as rice husk content increases. This informs that combustion is more difficult as rice husk content increases. Mass of residue 1 slightly increases when rice husk content increases from 0 to $30 \%$. After that, the mass of residue 1 significantly increases when rice husk content increases from 30 to $40 \%$. This shows that some elements are not completely combusted when the wood pellet contains 40 and 50\% rice husk. This is possibly due to the low combustion rate in higher rice husk content. In this circumstance, the activation energy, i.e. heat from the flame, is not sufficient to completely combust the wood pellet containing more rice husk. Correspondingly, the mass of residue 2 also increases as rice husk content increases and becomes more significant for rice husk content between 30 and $50 \%$.

\subsection{Combustion duration and rate}

This study investigates the combustion duration and rate since they are important characteristics. Combustion duration $(\mathrm{CD})$ depends on time of burner ignition $\left(\mathrm{t}_{0}\right)$, time of the flame outage $\left(\mathrm{t}_{\text {outage }}\right)$, and the ignition delay time (t $\left.\mathrm{t}_{\text {delay }}\right)$ (eq. 2).

$$
\mathrm{CD}=\mathrm{t}_{\text {outage }}-\mathrm{t}_{0}-\mathrm{t}_{\text {delay }}
$$

Meanwhile, the combustion rate $(\mathrm{CR})$ is function of initial pellet mass $\left(\mathrm{m}_{0}\right)$, mass of residue $1\left(\mathrm{~m}_{\text {res, } 1}\right)$ and combustion duration (eq. 3).

$$
\mathrm{CR}=\frac{\mathrm{m}_{\mathrm{res}, 1}-\mathrm{m}_{0}}{\mathrm{CD}}
$$

Wood pellet combustion comprises 4 consecutive steps, i.e. moisture vaporization, devolatilization, flame burning and char combustion. In the flame burning step, several processes take place, i.e. combustion of the mixture between vaporized volatile matter, combustion of a particular part of fixed carbon. The flame flares until it outages between the gasification step and the flame burning step while the char combustion step starts from the flame outage until the ember on the pellet outages [8]. Higher rice husk content of up to $30 \%$ results in higher combustion duration (Figure 4). After that, the combustion duration decreases and is relatively stable at app. 114.5 seconds. In this study, the combustion duration is determined only until the flame burning step and excludes the char combustion step.

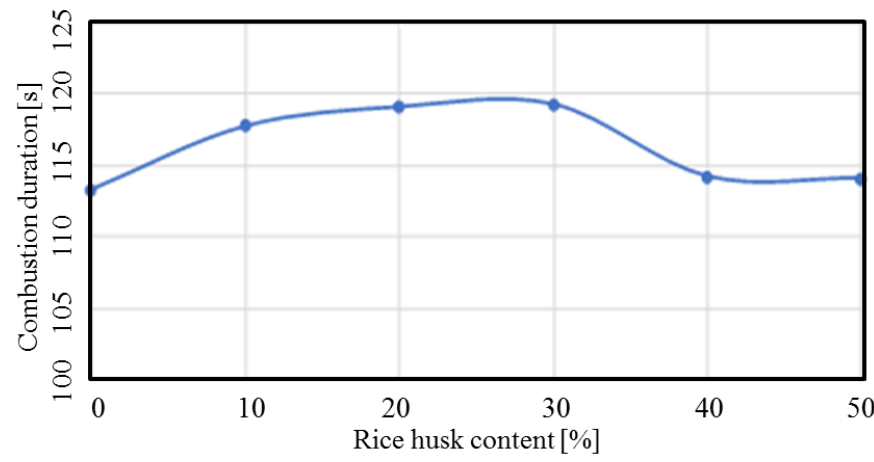

Figure 4: Influence of rice husk content of combustion duration 
As rice husk content increases, the combustion rate decreases (Figure 5). As a reference value, the combustion rate is $0.55 \mathrm{~g} / \mathrm{min}$ when no rice husk is added. The steepest combustion rate decrease occurs for $10 \%$ rice husk content. After that, the combustion rate slightly decreases until $50 \%$ rice husk content. The presence of rice husk seems to disturb heat transfer which decelerates vaporization and fuel combustion. This is shown with decreasing combustion duration and rate for pellets with 40 and $50 \%$ rice husk content. For both cases, the flame is already outage although many flammable elements are not fully combusted. The flame outage is due to a low combustion rate producing less heat. This less heat is not sufficient as the activation energy of the rest fuel in the flame burning step. After the flame outage, combustion continues as the ember combustion. The wood pellet with 40 to $50 \%$ rice husk content has a longer duration of ember combustion even though many flammable elements are not combusted.

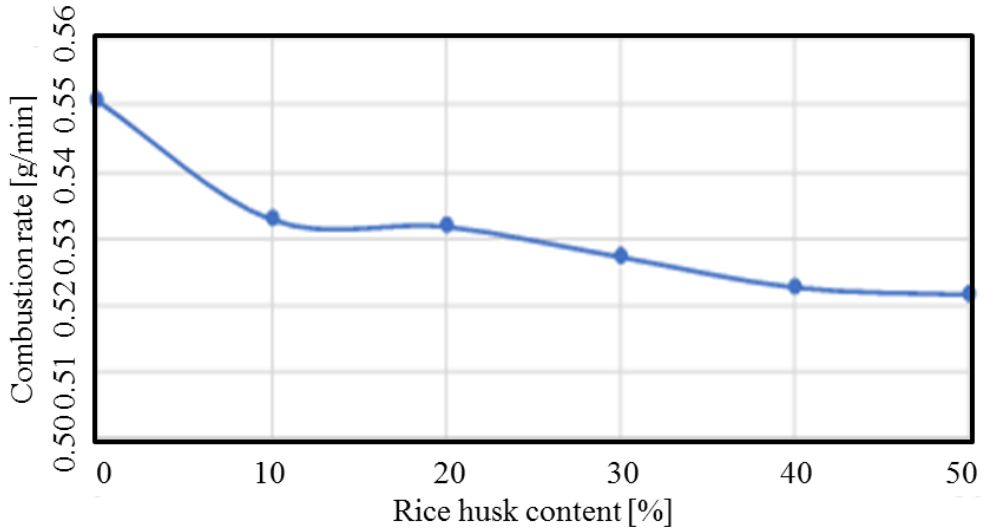

Figure 5: Influence of rice husk content of combustion rate

\subsection{Flame visualization}

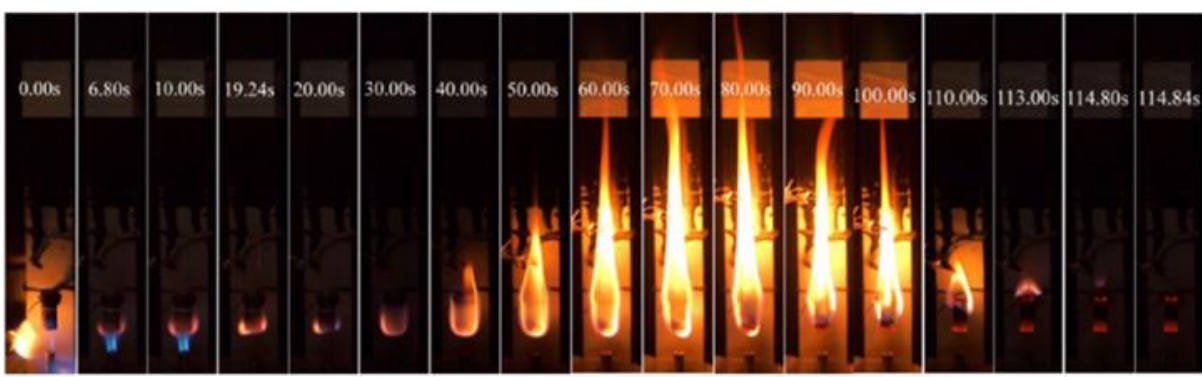

(a)

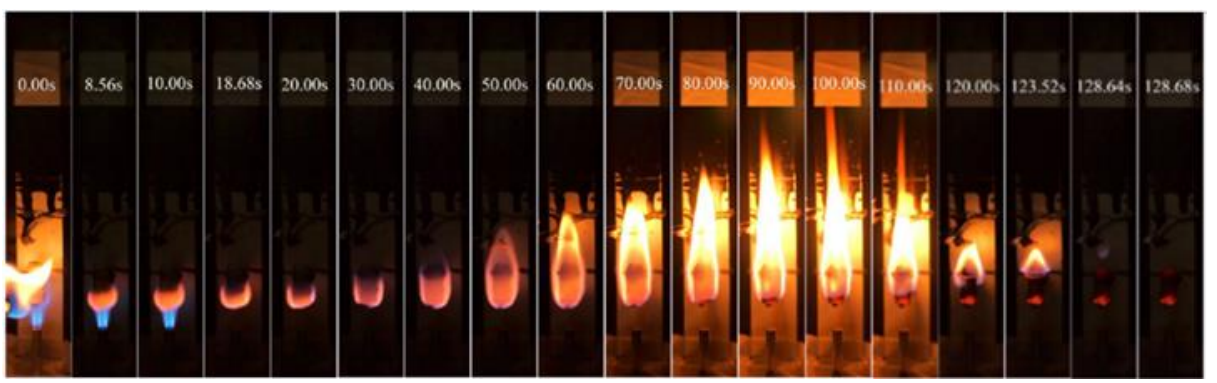

(b)

Figure 6: Flame visualization for the wood pellet containing $0 \%$ rice husk (a) and 30\% rice husk (b)

Flame visualization shows the flame development from the ignition time until the flame outage. Data of combustion duration previously discussed was gathered from analysis of flame visualization. Figure 6 depicts the flame visualization for 0 and $30 \%$ rice husk content. The flame height for the wood pellet without any addition of rice husk is $99 \mathrm{~mm}$, i.e. the highest compared to other mixtures (Figure 6a). In addition, the wood pellet with $0 \%$ rice husk content achieves its maximum flame height in the shortest time compared to other mixtures. For this reason, the wood pellet with $0 \%$ rice husk content also shows the highest combustion rate. 
For this mixture, flame height significantly increases after 40 seconds and achieves its maximum height after 80 seconds. Before 60 seconds, the early combustion step occurs. As the flame is significantly high between 60 and 100 seconds, the wood pellet combustion accelerates and releases much heat energy. After that, flame height slightly decreases until 100 seconds. After 100 seconds, flame height drops before its outage.

The flame heights of all wood pellet mixtures are presented in Figure 7. When rice husk is added, between 10 to $50 \%$, the flame height is between 60 to $70 \mathrm{~mm}$ which is much lower than in the wood pellet without any rice husk at $99 \mathrm{~mm}$. In addition, the mass of residues 1 and 2 also increase as the rice husk content increases. It can be then concluded that the addition of rice husk decreases the pellet quality. The pellet quality decreases further when rice husk content is 40 and $50 \%$.

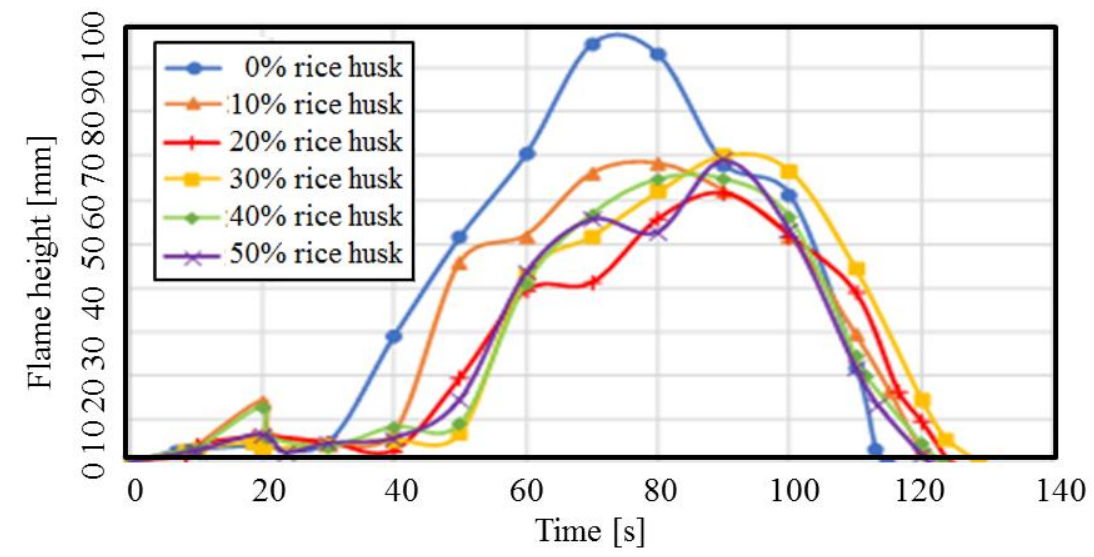

Figure 7: Influence of rice husk content on flame height

\subsection{Combustion temperature}

In this study, the flame temperature starts $(\mathrm{t}=0)$ when the igniter was ignited. In the beginning, the flexible thermocouple was located $10 \mathrm{~mm}$ above the wood pellet. After the flame was created, the height of flexible thermocouple changed following the flame height so that the maximum flame temperature can be accurately measured. In most cases, the flame temperature increases until the $20^{\text {th }}$ second but it significantly decreases until the $30^{\text {th }}$ second since the igniter was turned off (Figure 8). After that, the flame temperature increases again toward the maximum value for each mixture. After reaching its maximum value in app. $80^{\text {th }}$ second, the flame temperature decreases again. The maximum flame temperature for 0 to $30 \%$ rice husk content is between 800 and $850{ }^{\circ} \mathrm{C}$ while the maximum flame temperature for 40 and $50 \%$ rice husk content is in the range of 750 to $800{ }^{\circ} \mathrm{C}$.

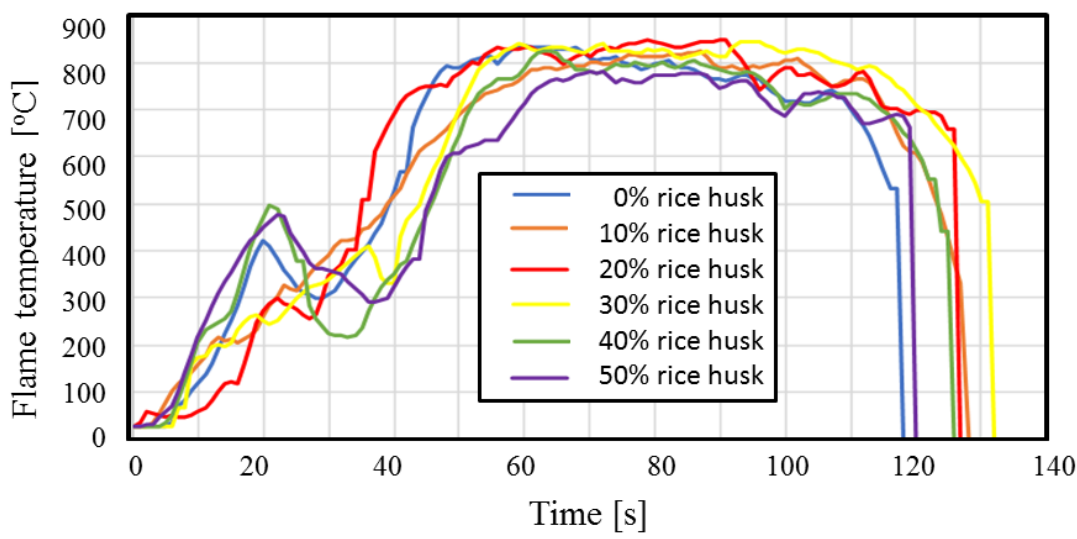

Gambar 8: Temperatur nyala api pada pembakaran wood pellet dengan variasi persentase sekam padi.

\section{CONCLUSION}

To reduce dependence on fossil fuel, biomass, e.g. the wood pellet, has been developed in recent years. This work investigates the combustion characteristics of the wood pellet made of Albizia Chinensis and rice husk in which the rice husk content varies between 0 to $50 \%$. As rice husk content increases from 0 to $50 \%$, the ignition delay time increases from 6 to 9.9 seconds, the mass of residue increases from 21.2 to $45 \%$ and the combustion rate decreases from 0.55 to $0.52 \mathrm{~g} / \mathrm{min}$. In addition, higher rice husk content also decreases the maximum temperature. 


\section{REFERENCES}

[1] WIBOWO, N.I., ARIEF, M.R.B., "Pemanfaatan teknologi tepat guna kompor roket dengan formulasi bahan bakar pelet kayu dan kayu sengon”, Agroscience, v. 10, n. 2, pp. 136-146, Des. 2020.

[2] MIAN, I., LI, X., DACRES, O.D., WANG, J., "Combustion kinetics and mechanism of biomass pellet", Energy, v. 205, 117909, pp. 1-10, 2020.

[3] The ministry of energy and mineral source of the Republic of Indonesia, http://iesr.or.id/wpcontent/uploads/2019/11/191216-IESR-Clean-Energy-Outlook.pdf, retrieved in August 2021.

[4] KLUSKA, D., TURZYNSKI, T., OCHNIO, M., KARDAS, D.," Characteristics of ash formation in the process of combustion of pelletised leather tannery waste and hardwood pellets", Renewable Energy, v. 149, pp. 1246-1253, 2020.

[5] STEVEN, S., RESTIAWATY, E., BINDAR, Y., "Routes for energy and bio-silica production from rice husk: A comprehensive review and emerging prospect", Renewable and Sustainable Energy Review, v. $149,111329,2021$

[6] LIU, Z., LIU, X., FEI, B., JIANG, Z., CAI, Z., \& YU, Y., “The properties of pellets from mixing bamboo and rice straw", Renewable Energy, v. 55, pp. 1-5, 2013.

[7] RÍOS-BADRÁN, I. M., LUZARDO-OCAMPO, I., GARCÍA-TREJO, J. F.,SANTOS-CRUZ, J., GUTIÉRREZ-ANTONIO, C., "Production and characterization of fuel pellets from rice husk and wheat straw”, Renewable Energy, v. 145, pp. 500-507, 2020.

[8] AHN, J., KIM, H. J., "Combustion process of a Korean wood pellet at a low temperature", Renewable Energy, v. 145, pp. 391-398, 2020. 